\title{
Patent ductus arteriosus-bicuspid aortic valve-hand anomalies syndrome
}

INSERM

\section{Source}

INSERM. (1999). Orphanet: an online rare disease and orphan drug data base. Patent

ductus arteriosus-bicuspid aortic valve-hand anomalies syndrome. ORPHA:228190

Patent ductus arteriosus - bicuspid aortic valve - hand anomalies syndrome is a very rare heart-hand syndrome (see this term) that is characterized by a variety of cardiovascular anomalies including patent arterial duct, bicuspid aortic valve and pseudocoarctation of the aorta in conjunction with hand anomalies such as brachydactyly and ulnar ray derivative i.e. fifth metacarpal hypoplasia. Transmission is most likely autosomal dominant. 